\title{
Cognitive reserve in healthy older adults
}

\begin{abstract}
Introduction: Cognitive reserve is a protective factor against neurodegenerative diseases with the capacity to modify the relationship between a pathology and its symptomatic manifestation. For this reason, its study in the elderly population is of great importance, as well as having an adequate scale to do so.
\end{abstract}

Objective: To describe and relate sociodemographic characteristics of cognitive reserve in older adults in the city of Buenos Aires throughout the Cognitive Reserve Questionnaire.

Methodology: Quantitative, observational, analytical, and cross-sectional design.

Sample: 174 older adults between 60 and 92 years old $(X=72.7 ; S D=7.4), 74 \%$ women

Results: Adequate values were found for the CRC reliability index (Cronbach's alpha: 0.72). The mean for cognitive reserve was 12.93 (SD: 4.6) indicating a medium-high cognitive reserve level. A positive and significant correlation of CRQ with semantic fluency, phonological fluency, CDT and MMSE was found. Differences in favor of men were found in the Studies, Languages, Occupation and Total Score dimensions. A linear regression indicates that CRQ score is significantly influenced by years of education.

Conclusion: The CRQ is a quick and reliable tool to assess levels of cognitive reserve and its use in neuropsychological assessment provides relevant information. In addition, education could stimulate the pursuit of intellectual enrichment and favor the cognitive and functional performance of older adults.

Keywords: cognitive reserve, healthy older adult, education, cognitive reserve questionnaire
Volume 6 Issue 2 - 202I

\author{
Grasso Lina,' Aceiro María Agustina,' \\ Aschiero María Belén,' González Aguilar,' \\ María Josefina,' Iglesia Fabiola, ${ }^{2}$ López \\ Magdalena ${ }^{2}$ \\ 'Research Center in Psychology and Psychopedagogy, Pontifical \\ Catholic University of Argentina, Argentina \\ ${ }^{2}$ Center for Interdisciplinary Research on Values, Integration and \\ Social Development (CIIVIDS), Teresa de Ávila Faculty, Pontifical \\ Catholic University of Argentina (UCA), Argentina
}

Correspondence: Lina Grasso, Research Center in Psychology and Psychopedagogy, Pontifical Catholic University of Argentina, Buenos Aires. Argentina (UCA), +549I I55040456, Email lina_graso@uca.edu.ar

Received: March 10, 202I | Published: March 26, 202 |

\section{Introduction}

Cognitive reserve is defined as the adult brain ability to minimize the clinical manifestation of a neurodegenerative process and its acquisition is associated with the performance of certain intellectual and cognitive activities throughout life. Several aspects influence brain and cognitive reserve, which are: years of schooling, IQ, lifetime occupation, hobbies, diet, and regular physical activity, as well as other variables related to healthy lifestyle habits. Cognitive reserve study arises from the discrepancies observed between the severity of anatomopathological damage and the degree of dysfunction of a subject. Some people with a significant level of brain atrophy on neuroimaging in their daily life do not show significant dysfunctionality, while, on the other hand, those who have lower levels of atrophy show greater dysfunctionality and earlier onset of symptoms. ${ }^{1-3}$ Therefore, cognitive reserve is described as a factor that allows understanding individual differences in the progression of neurodegenerative diseases such as Alzheimer's disease, thus considering it as a protective factor. ${ }^{4-6}$ As a result, cognitive reserve is understood as the differential way in which brain lesions are expressed in different people and is defined as the capacity of the human brain to adapt to a situation of injury, either through the use of preexisting cognitive resources, or through compensation resources and activation of new neural networks. ${ }^{7}$ Consequently, cognitive reserve can modify the relationship between a pathology and its symptomatic manifestation, ${ }^{6,8}$ as it is an individual variable, whose capacity is focused on facilitating alternative neural networks to the injured ones.

The definition of cognitive reserve arises from the concept of brain reserve, associated with the threshold theory that maintains that the same damage can generate reactions of different intensity according to the individual characteristics of each subject. The cognitive reserve models are supported by the explanation of a greater cerebral resistance that delays the appearance of symptoms (structural or "hardware" hypothesis, also called cerebral reserve) as well as alternative strategies to perform functionally well, despite the underlying pathological process (functional hypothesis or "software", also known as cognitive reserve). ${ }^{69}$ Therefore, both hypotheses are combined, postulating that those who have a greater cognitive reserve, have greater brain volume and greater efficiency in solving environmental demands and neurocognitive tests. ${ }^{2,7}$ Since it is not yet possible to map, correlate, and integrate biological, cellular, and molecular mechanisms with functional ones, Stern et al. ${ }^{6}$, point out the convenience of using the term wetware to refer to the amalgamated interaction between hardware and software.

This construct is related to different variables, mainly with the years of education. ${ }^{10-14}$ It is also linked to socio-environmental variables such as intellectual level, occupation, hobbies and other variables associated with healthy habits, such as nutritional habits, physical activity, intellectual playful activity, parental relationship, social habits and environmental enrichment..$^{8,9,11,15-20}$ It is pointed out that leisure activities, lifestyle and intelligence are directly related to the cognitive reserve, while schooling and socioeconomic level do so indirectly. ${ }^{21}$ Therefore, the study of these variables is relevant for a better understanding of the course of neurodegenerative diseases, such as mild cognitive impairment (MCI) or Alzheimer's disease. ${ }^{2,4,5}$

In a recent review about instruments to assess cognitive reserve, Landenberger et al. ${ }^{22}$ mention the Cognitive Activities Scale (LCAS); ${ }^{23}$ the Lifetime of Experiences Questionnaire (LEQ) ${ }^{24}$ the Cognitive Reserve Index Questionnaire (CRIQ)25; the Cognitive Reserve Scale $(\mathrm{CRS})^{26,27}$ and the Cognitive Reserve Questionnaire - CRQ. ${ }^{1}$ The LCAS $^{2}$ test proposes to measure cognitive reserve in five stages of life, according to the level of participation in activities such as reading, games, etc. However, they do not include variables of 
educational and professional level. It is a Likert-type response scale $(0-5)$. On the other hand, the LEQ questionnaire ${ }^{3}$ assesses education, occupation, play, musical instrument, arts, reading, social life, sports, languages, travel and hobbies; in three life stages (young adult, adult and older adult). It includes 42 items with a Likert type response (05). Another questionnaire used is the CRIQ ${ }^{4}$ which studies education, work activity and free time activity (intellectual, social and physical). It measures the number of years in which the participant carried out these activities from the age of 18 . Finally, the CRS, ${ }^{5}$ a 24 -item questionnaire with a Likert type response, contemplates the activities of daily life, training, information, hobbies, and social life in three vital stages. Nevertheless, variables of educational and professional level are not included.

The Cognitive Reserve Questionnaire (CRQ) ${ }^{1}$ is a useful questionnaire to assess the level of cognitive reserve in older adults. It consists of an 8-item quick assessment, closely related to the cognitive reserve that considers different aspects of the experience throughout life. The CRQ is associated with the cognitive performance of executive functions and the years of education, as in both groups significant correlations were found between the CRQ score and performance on neuropsychological tests that measure executive function. This questionnaire offers normative values for the cognitively healthy elderly Spanish population. Previous studies indicate the usefulness of this questionnaire due to its easiness and quickness in its administration, since it offers an estimate of parameters related to the formation of cognitive reserve belonging to the intellectual area in Spanish-speaking older people. , $, 6,7$ On the other hand, the CRQ is a useful tool to include in neuropsychological evaluation and in research to evaluate protective factors that could delay the expression of neurobiological changes of age and neurodegenerative diseases.

Finally, the aim of this research was to describe and relate sociodemographic characteristics of the cognitive reserve of older adults in the City of Buenos Aires (language, parents' education, work occupation, training courses, musical training, reading activity and recreational activity) throughout the Cognitive Reserve Questionnaire. ${ }^{1}$

\section{Material and method}

The present research had a quantitative, observational, analytical, and cross-sectional methodological approach. The sample was easily accessible to the researcher, as it consisted of non-institutionalized older adults of medium socioeconomic level from the Autonomous City of Buenos Aires. The inclusion criteria were adults from 60 to 95 years old, of both sexes and self-validating, without cognitive impairment according to 1) cognitive screening and 2) emotional considerations (see instruments). All participants included in the sample agreed to participate voluntarily and signed the informed consent.

The final sample consisted of 174 older adults between 60 and 92 years old $(X=72.7 ; S D=7.4)$, with $74 \%$ women $(\mathrm{N}=128)$.

\section{Instruments}

\section{Evaluation of inclusion criteria}

\section{Cognitive screening}

Mini Mental State Examination (MMSE), is a short test used for tracking initial cognitive decline that allows a quick and standardized evaluation of the cognitive alterations. ${ }^{8-11}$
Verbal fluency:12,13 categorical evocation test (phonological or semantic) sensitive in detecting the presence of cognitive impairment.

Clock Drawing Test: ${ }^{14,15}$ sensitive test for the detection of cognitive impairment and Alzheimer's disease.

\section{Emotional considerations}

Yessavage Geriatric Depression Scale - GDS: ${ }^{16,17}$ scale for the assessment of depressive symptoms in older adults. It evaluates 5 areas: somatic complaints, cognitive complaints, motivation, future and past orientation, and loss of self-image. ${ }^{18}$ The 15 -item abbreviated version was used, each is valued as Yes- 1 / No- 0 , and the total score is the sum of the items. Scores less than 4 indicate absence of depression, between 4 and 6 points indicate mild depression, and scores greater than 7 indicate depression as psychiatric pathology-established depression. In his study, using the 15-item version, internal consistency yielded a satisfactory Kuder Richardson Coefficient $(K R-20=0.57)$.

\section{Evaluation of the cognitive reserve}

Cognitive Reserve Questionnaire (CRQ): ${ }^{1}$ measures the level of cognitive reserve. It was designed on the basis of eight dimensions that correspond to the predictive factors of brain and cognitive reserve reported in the literature: schooling; conducting training courses; the schooling of the parents; the work occupation carried out throughout life; musical training; knowledge of languages; the approximate frequency with which cognitively stimulating activities have been carried out throughout life (intellectual games, such as crosswords and chess) and reading activity (frequency and practice). Their scores range from 0 to 25 points and, the higher the score, the more evidence of cognitive reserve factors. For this study, the individual scores in each of the 8 dimensions taken as predictive factors and the total score were considered to perform the correlation and multiple regression analysis.

\section{Analysis of results}

The SPSS 26 version program was used. Descriptive analysis of sociodemographic variables, cognitive screening, emotional aspects (inclusion criteria) and cognitive reserve of the participants were carried out. The frequencies, measures of central tendency (mean) and dispersion (standard deviation) were analyzed. Bivariate correlations (Pearson) were performed.

\section{Procedure}

The participants were individually evaluated in a 30-minute meeting by psychologists previously trained in the administration of the mentioned techniques. The delimitation of the final sample was made based on the application of cognitive screening, then the evaluation of the state of mind in a previous interview and, finally, the application of the cognitive reserve scale. Prior to the evaluation, informed consent and the information sheet were provided to older adults interested in participating.

\section{Results}

Older adults had a mean of 12.3 years of education, with a standard deviation of $4.9 ; 56.9 \%$ of the participants had completed their secondary studies $(\mathrm{N}=99)$. Most participants presented an educational level between medium and high: $40.2 \%(\mathrm{~N}=70)$ finished secondary school, $43.8 \%(\mathrm{~N}=75)$ had tertiary or university studies and only $16.7 \%(\mathrm{~N}=29)$ had primary studies. Regarding the work complexity of the participants, $78 \%$, that is, the majority $(\mathrm{N}=153)$, were involved in skilled occupations throughout their lives and among them, 38.2\% 
$(\mathrm{N}=68)$ were professional or managerial positions. Regarding the education of the parents of the elderly, $51.1 \%(\mathrm{~N}=91)$ reached basic or primary education, $38.2 \%(\mathrm{~N}=68)$ accessed higher or university education and $8.6 \%(\mathrm{~N}=15)$ did not receive formal education.

Table 1 shows the distribution of the level of education and other sociodemographic data evaluated. Adequate values of the CRQ reliability index (Cronbach's alpha: 0.72) were observed, that is, the internal consistency of the items is acceptable and allows us to affirm that they evaluate cognitive reserve. Regarding the level of cognitive reserve, the mean obtained by the group was 12.93 points, with a deviation of 4.6 points. According to the classification by quartiles of the original $\mathrm{CRQ}^{2}$, the score obtained in the present study is equivalent to quartile 3 , corresponding to the level of medium-high cognitive reserve.

Table I Sociodemographic characteristics and description of the sample

\begin{tabular}{|c|c|c|c|}
\hline & & Frecuency & $\%$ \\
\hline \multirow[t]{2}{*}{ Gender } & Male & 46 & 26 \\
\hline & Female & 128 & 74 \\
\hline \multirow[t]{3}{*}{ Education level } & Up to elementary school complete & 29 & 16,7 \\
\hline & High school complete & 70 & 40,2 \\
\hline & University & 75 & 43,1 \\
\hline \multirow[t]{5}{*}{ Occupation } & Not qualified / Housewife & 21 & 12.1 \\
\hline & Manual Qualified & 32 & 18.4 \\
\hline & Non-manual qualified & 53 & 30.5 \\
\hline & Professional & 50 & 28.7 \\
\hline & Manager & 18 & 10.3 \\
\hline \multirow[t]{3}{*}{ Parental education level } & Uneducated & 15 & 8.6 \\
\hline & Elementary & 91 & 52.3 \\
\hline & College or university & 68 & 39.1 \\
\hline \multirow[t]{2}{*}{ Family history of psychiatric disease } & Yes & 32 & 18.4 \\
\hline & No & 142 & 81.6 \\
\hline \multirow[t]{2}{*}{ Family history of neurological diseases } & Yes & 38 & 21.8 \\
\hline & No & 136 & 78.2 \\
\hline
\end{tabular}

Regarding cognitive performance, positive and significant correlations were found in the score of the cognitive reserve questionnaire with semantic fluency $(r=.324 ; p<.001)$; phonological fluency $(r=.317 ; p<.001)$; the MMSE $(r=.172 ; p=.0245)$; CDT $(r=$ $.175 ; p=.021)$, evidencing that, the higher the score is in the cognitive tests, the higher the cognitive reserve is (Table 2).

Table 2 Description of scores obtained in cognitive screening tests

\begin{tabular}{ll}
\hline & Mean (DS) \\
\hline MMSEI & $28.5(1.3)$ \\
CDT2 & $8.8(1.6)$ \\
SVF3 & $16.9(5.1)$ \\
PVF4 & $14.65(4.4)$
\end{tabular}

'Mini mental state examination, ${ }^{2}$ Clock drawing test, ${ }^{3}$ Semantic verbal fluency; ${ }^{4}$ Phonemic verbal fluency; DS: standard deviation
With regards to age, only a positive (weak) relationship was found with the Reading Activity dimension $(r=.204 ; p=.007)$, trend that tends to increase in advanced ages.

Regarding sex, differences were analyzed using Student's T test for independent samples and a higher score was found, in favor of men in the Studies dimension $(X: 4.46, S D: 0.88 ; t: 3.01, d f: 172, p=$, 003 ); Languages ( $X: 1.15, S D: 1.19 ; t: 3.26, d f: 172, p<.001)$; Work occupation $(X: 2.78, S D: 1.11 ; t: 5.16, d f: 172, p<.001)$ and in the total score of the scale $(X: 14.16, S D: 5.17 ; t: 2.29, d f: 172, p=.023)$. Moreover, women scored higher in Recreational Activity $(X: 0.87$, $S D: 0.82 ; t:-2.8, d f: 172, p=.005)$, compared to men.

Meanwhile, in the relationship between cognitive reserve and years of education, a positive correlation was found with the total CRQ score $(p<.001)$, but not with age and sex. A similar trend was found with the dimensions of the CRQ, finding a positive correlation between the total score of the scale and all the dimensions, except for the musical training dimension (Table 3). 
Table 3 Correlation analyses between education, RC score and RC dimensions

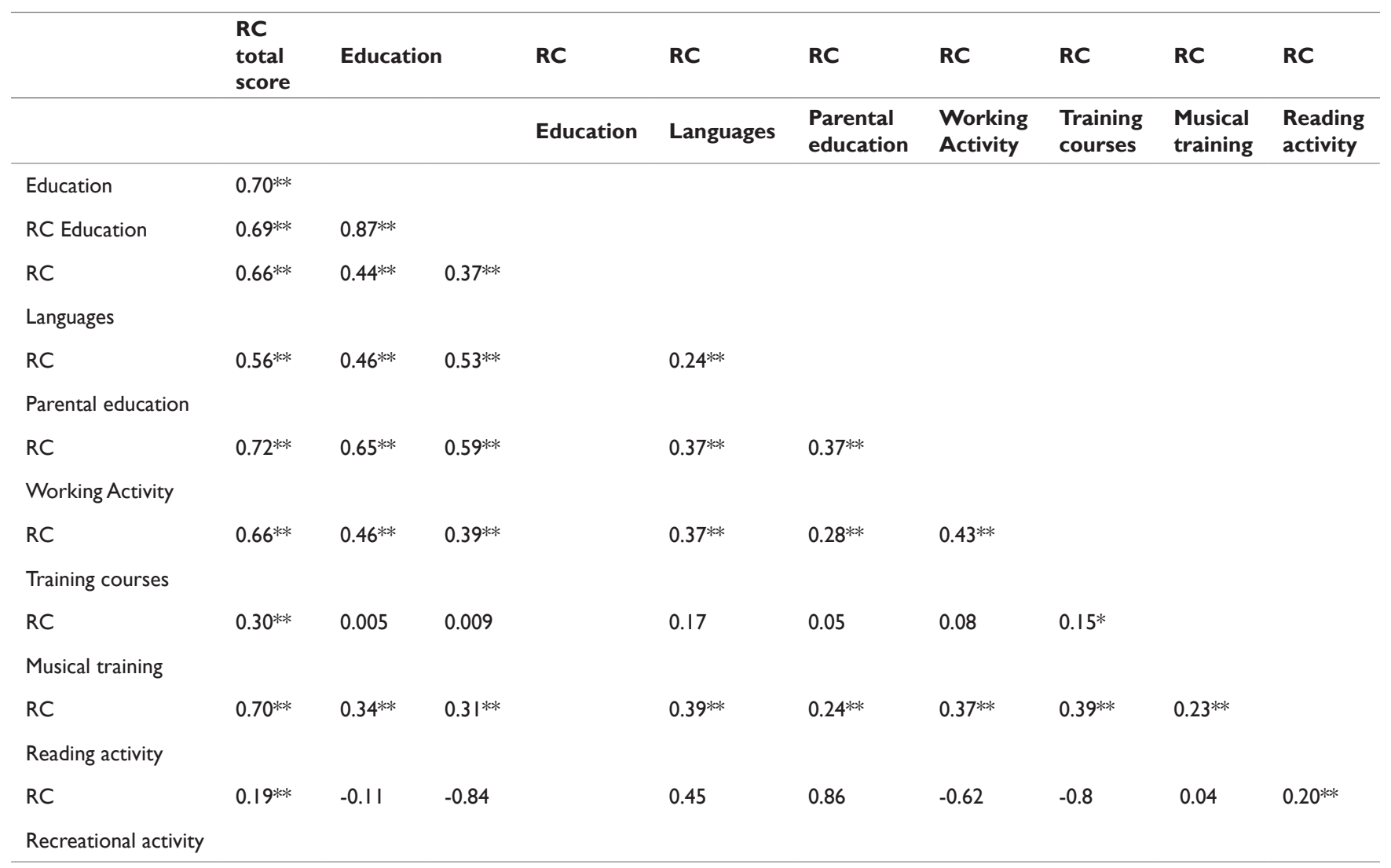

$*=<.05$ Correlation statistically significant; $* *=<.0$ I Correlation statistically significant

\section{Discussion}

Research on contextual and personal factors related to cognitive reserve in Spanish-speaking older adults is still scarce. The CRQ ${ }^{1}$ was used, to make a first approach to its study through the main variables studied in the literature in the Argentine elderly population.

The characteristics of the sample revealed that most of the participants had an educational level between medium and high, most of whom were dedicated to qualified occupations throughout their lives. In general, they came from families with parents who had reached a medium to high level of education, which made it possible to show that they belonged to middle socioeconomic level. Most people did not report a history of psychiatric or neurological diseases, did not present symptoms of depression and had good cognitive performance. Additionally, according to the classification by quartiles of the original scale, ${ }^{1}$ it is shown that the total score obtained from the CRQ is equivalent to a medium-high level of cognitive reserve. Notably, it was evidenced that the evaluated sample presents characteristics of a population with social, physical and cognitive advantage, characteristics associated with a lower probability of pathological aging.

Regarding sex and age, differences were found only in some dimensions, but not with the total score of the scale. The study of these differences requires larger samples from various socioeconomic levels and with a similar number of participants in both groups.

In the statistical analysis of the CRQ, the years of schooling of older adults were considered and, as in previous studies, the results showed that education is a good predictor of cognitive reserve and cognitive performance..$^{1,7,19-25}$ This finding could be explained by the importance of formal education for the development of the cognitive reserve. Indeed, similar trends were reported in populations with a lower level of education, pointing out the importance of promoting education and stimulating intellectual capacity in the early stages of life. $^{7}$

\section{Conclusion}

The results of this research corroborate that the CRQ is a useful, simple, and rapidly applied instrument to include in neuropsychological evaluation and in research to evaluate protective factors that delay the expression of neurobiological changes of age and neurodegenerative diseases. Additionally, it provides information about different factors related to the cognitive reserve of the elderly adult in which, in addition to education, other factors that have proven to be important at the time of its evaluation are considered, such as the education of the parents, knowledge of languages, study of languages, reading habits, etc. . $^{19,22,25-29}$

Previous studies suggested that education could stimulate the search for intellectual enrichment and that, in turn, this would favor the cognitive and functional performance of the elderly. Therefore, future research should delve into the study of the differences found in the dimensions (ie: reading activity as age increases; recreational activity in women) and their relationship with other variables such as intellectual capacity and cognitive performance to promote their development from an early age..$^{30-39}$

\section{Acknowledgments}

None. 


\section{Conflicts of interest}

The authors declare that there is no conflict of interest.

\section{References}

1. Katzman R, Aronson M, Fuld P, et al. Development of dementing illnesses in an 80-year-old volunteer cohort. Ann Neurol. 1989; 25:317-324.

2. Rami L, Valls-Pedret C, Bartrés-Faz D, et al. Cuestionario de reserva cognitiva. Valores obtenidos en población anciana sana y con enfermedad de Alzheimer. Rev Neurol. 2011;52(4):195-201.

3. Snowdon D. Healthy aging and dementia: findings from the Nun Study. Ann Intern Med. 2003;139:450-454.

4. Berthier ML, Dávila G. Anticipando el futuro: diagnóstico de la enfermedad de Alzheimer en las fases predemencia y prodrómica. Rev Neurol. 2010;51:449-450.

5. Valls-Pedret C, Molinuevo JL, Rami L. Diagnóstico precoz de la enfermedad de Alzheimer: fase prodrómica y preclínica. Rev Neurol. 2010;51:471-480.

6. Stern Y, Arenaza-Urquijo EM, Bartrés-Faz D, et al. Whitepaper: defining and investigating cognitive reserve, brain reserve, and brain maintenance. Alzheimers Dement. 2018;16(9):1305-1311.

7. Lojo-Seoane C, Facal D, Juncos-Rabadán O. ¿Previene la actividad intelectual el deterioro cognitivo? Relación entre reserva y deterioro cognitivos ligero. Rev Esp Geriatr Gerontol. 2012; 402:1-9.

8. Vazquez M, Rodriguez A, Villareal JS, et al. Relación entre la reserva cognitiva y el enriquecimiento ambiental: una revisión del aporte de las neurociencias a la comprensión del envejecimiento saludable. Cuad. Neuropsicol. 2014; 8(2):171-201.

9. Rodriguez AM, Sánchez RJ. Reserva cognitiva y demencia. An de Psicol. 2004;20(2):175-186.

10. Andel R, Vigen C, Mack WJ, et al. The effect of education and occupational complexity on rate of cognitive decline in Alzheimer's patients. J Int Neuropsych Soc. 2006;12:147-152.

11. Stern Y. What is cognitive reserve? Theory and research application of the reserve hypothesis. J Int Neuropsych Soc. 2002; 8:448-460.

12. Stern Y, Gurland B, Tatemichi TK, et al. Influence of education and occupation on the incidence of Alzheimer's disease. JAMA. 1994; 271:1004-1010.

13. Wilson RS, Barnes LL, Bennett DA. Assessment of lifetime participation in cognitively stimulating activities. $J$ Clin Exp Neuropsychol. 2003;25:634-642.

14. Carnero C, Del Ser T. La educación proporciona reserva cognitiva en el deterioro cognitivo y la demencia. Neurol. 2007;22:78-85.

15. Plassman BL, Welsh KA, Helms M, et al. Intelligence and education as predictors of cognitive state in late life: a 50-year follow up. Neurol. 1995;45:1446-1450.

16. Stern Y, Albert S, Tang MX, et al. Rate of memory decline in AD is related to education and occupation: cognitive reserve? Neurol. 1999;53:19421947.

17. Helzner EP, Scarmeas N, Cosentino S, et al. Leisure activity and cognitive decline in incident Alzheimer disease. Arch Neurol. 2007; 64:1749-1754.

18. Féart C, Samieri C, Rondeau V, et al. Adherence to a Mediterranean diet, cognitive decline, and risk of dementia. JAMA. 2009; 302:638-648.

19. Scarmeas N, Luchsinger JA, Schupf N, et al. Physical activity, diet and risk of Alzheimer disease. JAMA. 2009;302:627-637.

20. Hughes T, Ganguli M. Factores de riesgo de demencia en la vejez modificables en las etapas medias de la vida. Rev Neurol. 2010; 51:259_ 262.
21. Cuesta C, Cossini FC, Politis DG. Reserva cognitiva: revisión de su conceptualización y relación con la enfermedad de Alzheimer. Subjetividad y procesos cognitivos. 2019;23(2):166-185.

22. Landenberger T, Cardoso NDO, Oliveira CRD, et al. Instrumentos de medida de reserva cognitiva: una revisión sistemática. Psicol.: Teor. Prát. 2019;21(2):58-74.

23. Wilson RS, Li Y, Aggarwal NT, et al. Education and the course of cognitive decline in Alzheimer disease. Neurol. 2004; 63:1198-1202.

24. Valenzuela MJ, Sachdev P. Assessment of complex mental activity across the lifespan: development of the Lifetime of Experiences Questionnaire (LEQ). Psychol Med. 2007;37:1015-1025.

25. Nucci M, Mapelli D, Mondini S. Cognitive Reserve Index Questionnaire (CRIq): A new instrument for measuring cognitive reserve. Aging Clin Exp Res. 2011;24(3):218-226.

26. León-Estrada I, García J, Roldán-Tapia L. Development of the scale of cognitive reserve in Spanish population: A pilot study. Rev Neurol. 2011;52(11):653-660.

27. León-Estrada I, García-García J, Roldán-Tapia L. Escala de reserva cognitiva: Ajuste del modelo teórico y baremación. Rev Neurol. 2017; $.64: 7-16$.

28. Vásquez M. Factores predictores de la reserva cognitiva en un grupo de adultos mayores. Rev Chil Neuropsicol. 2016;11(1):5-11

29. Allegri RF, Ollari JA, Mangone CA, et al. El mini mental state examination en la argentina: instrucciones para su administración. grupo de trabajo de neuropsicología: sociedad neurológica Argentina. Rev Neurol Arg. 1999;24(1):31-35.

30. Butman J, Allegri R, Harris P, et al. Fluencia verbal en español, datos normativos en Argentina. Medicina. 2000;60(5):561-564.

31. Folstein MF, Folstein SE, McHugh PR. Mini-mental state. A practical method for grading the cognitive state of patients for the clinician. J Psychiatr Res. 1975;12:189-198.

32. Lobo A, Saz P, Marcos G, et al. Revalidación y normalización del Mini Examen Cognitivo (primera versión en castellano del Mini-Mental Status Examination) en la población general geriátrica. Med Clin. 1999;11:767774.

33. Butman J, Arizaga RL, Harris P, et al. El mini mental state examination en español. normas para buenos aires. Rev Neurol Arg. 2001;26:11-15.

34. Carnero-Pardo C, Lendínez-González A. Utilidad del test de fluencia verbal semántica para el diagnóstico de demencia. Rev Neurol Arg. 1999;29:709-714.

35. Cacho J, García-García R, Arcaya J, et al. Una propuesta de aplicación y puntuación del test del reloj en la enfermedad de Alzheimer. Rev Neurol. 1999;28(7):648-655.

36. López N, Allegri R, Soto-Añari M. Capacitación diagnóstica y validación preliminar del Test del Reloj, versión de Cacho a la orden para la Enfermedad de Alzheimer grado leve en Población Chilena. Rev Ecuat Neurol. 2014;23:1-3.

37. Martínez de la Iglesia J, Onís Vilches MC, Dueñas Herrero R, et al. Versión española del cuestionario de Yesavage (GDS) para el despistaje de depresión en mayores de 65 años: adaptación y validación. MEDIFAM. 2002;12(10):620-630.

38. Tartaglini MF, Dillon C, Hermida PD, et al. Prevalence of Geriatric Depression and Alexithymia and their association with sociodemographic characteristics in a sample of elderly persons living in Buenos Aires, Argentina. Rev Bras Geriatr. Gerontol. 2017; $20(4$ ):516-524.

39. Yesavage JA, Brink TL, Rose TL,,et al. Development and validation of a geriatric depression screening scale: A preliminary report. $J$ Psychiatr Res. 1983;17:37-49. 